Clinics in Haematology. Vol 10 no. 1 Feb. 1981 Enzymopathies.

Edited by William C. Mentzer. Pp. 256, illustrated. W. B. Saunders, London, Philadelphia, Toronto, 1981. £9.75 (single issue) $\mathfrak{f} 19.50$ (subscription).

The knowledge of red cell enzymopathies amongst most haematologists is rather rudimentary and usually confined to glucose- 6 phosphate dehydrogenase and pyruvate kinase deficiency. This book, written by a number of authors who are experts in the field sets out to discuss not only the haemolytic anaemias caused by red cell enzymopathies, but also gives a comprehensive account of other human erythrocyte metabolic abnormalities, many of which manifest themselves as 'non-erythrocyte disorders'.

The chapter on diagnostic strategy in a suspected case of red cell enzymopathy is excellent. There is good coverage of enzymopathies in neonates, pyruvate kinase, and other Embden-Meyerhoff pathway enzyme deficiencies and haemolysis associated with purine and pyrimidine salvage pathways and methaemoglobinaemia. Rarer topics like red cell enzyme abnormalities in dyserythropoiesis and malignant diseases are adequately dealt with. More esoteric topics such as the use of red cell enzyme polymorphism in genetics and forensic medicine are discussed, but these would not be of much interest for the majority of haematologists.

The main criticism of this book is that G6PD deficiency, which is the commonest and clinically most significant abnormality, has been dealt with in a most perfunctory manner.

The book, though full of information, is rather hard to read, and many facts are repeated. It is difficult to see at whom this book is aimed. In spite of these criticisms it will make a most useful reference volume.

A. J. BARRETT

Westminster Medical School, London SWI.

\section{Intestinal Obstruction}

by HAROLD Ellis with contributions from J. F. ZILVA, D. FORREST and J. GLEESON. Pp. 367, illustrated. Appleton-CenturyCrofts, New York. Prentice-Hall International, Hemel Hempstead, Herts, 1982. £36.40.

In these days of multi-author books and mass produced reports of esoteric symposia, what a great pleasure it is to pick up a beautifully produced, well bound, no nonsense monograph (albeit with the help of a few friends). Intestinal Obstruction is a comfortable book, reminiscent of medical publications of years ago. It presents an exhaustive review of the literature on the subject written in a clear, concise, easy-to-read style which is the hall mark of a good teacher.

It is difficult to criticize such a book in which reports of scientific studies and clinical experience are clarified by concise expression of the author's opinion of the debate. Of course it is inevitable that there are some moments of confusion. I was surprised to read in these days when every penny spent on investigation and management of patients must be justified that: "plain X-ray of the abdomen should be performed routinely in all cases of intestinal obstruction'. This traditional indoctrination is unquestioned until later in the test where one reads: 'after a clinical diagnosis of obstruction is made, even in the face of normal radiology and without anything to suggest strangulation, the best treatment is still urgent surgery'. Thus I am sure Professor Ellis would forgive, and perhaps even applaud, a resident who submitted a patient to laparotomy after making a diagnosis of intestinal obstruction on clinical grounds without an abdominal X-ray.

In summary, this is a delightful book for all practising surgeons to read for no one will leave it without having picked up some valuable pearls of wisdom. So valuable is it, especially to the on-call surgical resident, that I think it should be placed on his bedside table alongside the Gideon's Bible. However, I rather suspect that at $£ 36.40$ a copy most hospital authorities will balk at this proposal.

K. E. F. HOBBS

Royal Free Hospital School of Medicine,

London NW3

\section{Organic Acids in Man}

By R. A. Chalmers and A. M. Lawson. Pp. 523, illustrated. Chapman and Hall, London, 1982. £35.00.

This is not, as its title might suggest, a treatise on intermediary metabolism, but a handbook for the chemical pathologist analysing urine or other body fluids from patients, usually children, with inborn errors of metabolism. The authors rightly regard their work as a successor to the 1961 review of the same subject by $J$. and $R$. Nordmann, but whereas the earlier work was predominantly concerned with column and paper chromatography, this book is eight times as long and deals mainly with gas chromatography and mass spectrometry. As techniques improve, new diseases characterized by an abnormal organic aciduria continue to be discovered, and the subject has become so complex that it is beyond the stage where the clinician involved can master the practical techniques necessary for diagnosis. Neither of the present authors is medically qualified. nor do they seem to be biochemists in the conventional sense, and the sections of the book which are concerned with clinical presentation and intermediary pathways are sketchy and appear to be included to place the analytical sections firmly in context. The book's appeal will therefore be mainly to laboratory workers facing these analytical problems, and here it should prove invaluable as it is readable and comprehensive, with over a thousand references and fifty pages of appendices containing mass spectrometric and gaschromatographic data. For so much information the price is reasonable.

Organic acids of bacterial origin seem to be beyond the brief chosen by the authors, but as a reviewer I cannot entirely forget my special interests. The highest concentrations of organic acid in the body, up to $200 \mathrm{mmol} /$ litre, are those of short-chain fatty acids in the large intestine, not mentioned here even in sections on 'other fluids' or 'volatile carboxylic acids'. These acids are derived by bacteria action from mainly carbohydrate precursors, and are rapidly absorbed through the mucosa, so entering into the metabolism of the body and deserving a passing mention.

\section{University College London, London WC1}

Vaccination Certificate Requirements for International Travel and Health Advice to Travellers. Situation as on 1 January 1981

pp. 65. World Heath Organization, Geneva, 1981. Sw.fr. 18.00

For many years, the World Health Organization published a booklet on the vaccination certificate requirements for international travel. This consisted of a list of the statutory and recommended vaccinations required for entry into the countries named.

With the acceptance by the World Health Assembly in May 1980 of the eradication of smallpox and the deletion of the requirement for a cholera certificate in 1973, this only left yellow fever certificate as a requirement for international travel. Long lists of countries and their vaccination requirements no longer seemed appropriate and in 1982 the World Health Organization changed the format of its familiar annual publication to include the wider health risks of foreign travel.

Separate sections of this booklet deal with the dangers of environmental effects, risk of infection from food and drink, sexually transmitted diseases, hazards from arthropods and also animal associated diseases. Much fuller information is given on the current malaria situation. For each zone the common diseases most likely to be encountered are briefly described together with health advice on the precautions which may be usefully taken.

All in all, this brief booklet of no more than 70 pages gives most informative and up-to-date advice on the risks associated with international travel and it should prove invaluable for general practitioners who have to deal with patients travelling abroad, together with community health physicians and medical officers of firms sending large numbers of people abroad.

L. ROODYN

Hospital for Tropical Diseases, London NW1 